\title{
Chinese Herbal Medicine for Psoriasis: Evidence From 11 High-Quality Randomized Controlled Trials
}

\author{
Yue Luo ${ }^{1,2+}$, Jiale Chen ${ }^{1,2 \dagger}$, Le Kuai ${ }^{1,2}$, Ying Zhang ${ }^{1,2}$, Xiaojie Ding ${ }^{1}$, Ying Luo ${ }^{2}$, Yi Ru ${ }^{2}$, \\ Meng Xing ${ }^{1}$, Hongjin $\mathrm{Li}^{2}$, Xiaoying Sun ${ }^{2}$, Bin $\mathrm{Li}^{1,3 *}$ and Xin $\mathrm{Li}^{1,2 *}$
}

${ }^{1}$ Department of Dermatology, Yueyang Hospital of Integrated Traditional Chinese and Western Medicine, Shanghai University of Traditional Chinese Medicine, Shanghai, China, ${ }^{2}$ Institute of Dermatology, Shanghai Academy of Traditional Chinese Medicine, Shanghai, China, ${ }^{3}$ Shanghai Dermatology Hospital, Tongji University, Shanghai, China

Background: Chinese herbal medicine $(\mathrm{CHM})$ provides a theoretical basis for the treatment of psoriasis with considerable benefits and a low toxicity. The purpose of this quantitative study was to show high-quality evidence of the efficacy and safety of $\mathrm{CHM}$ for the treatment of psoriasis to promote its clinical application.

Methods: Several databases were systematically searched including PubMed, Embase, Cochrane Central Register of Controlled Trials, China Network Knowledge Infrastructure, Chinese Scientific Journals Database, and Wan Fang Database. High-quality randomized controlled trials that compared $\mathrm{CHM}$ with non-CHM interventions were included. The RevMan5.3 software was used to calculate risk ratios (RR) at 95\% confidence intervals (Cl) and conduct the meta-analysis.

Results: Altogether, 1,215 patients participated in this study, including 711 in the experimental group and 504 in the control group. The psoriasis area severity index (PASI) score of the CHM group was significantly lower than that of the placebo group (MD, $-4.02 ; 95 \% \mathrm{Cl},-6.71$ to $-1.34 ; p=0.003$ ). To achieve PASI-60 and PASI-75, the arrival rate of the CHM group was higher than that of the placebo group (PASI-60: RR, 3.52; 95\% Cl, 1.17 to $10.61 ; p=0.03$; PASI-75: RR, 9.87; 95\% Cl, 3.11 to $31.31 ; p=$ 0.0001). Furthermore, the efficacy rate was higher in patients receiving $\mathrm{CHM}$ than in those receiving placebo $(\mathrm{RR}, 1.72 ; 95 \% \mathrm{Cl}, 1.01$ to $2.93 ; p=0.04)$. The results suggested a greater impact of $\mathrm{CHM}$ in improving the dermatology life quality index (DLQI) of patients $(\mathrm{MD},-2.12 ; 95 \% \mathrm{Cl},-3.75$ to $-0.49 ; p=0.01$ ). Regarding pruritus severity, there was no significant difference between the two groups (MD, $-1.90 ; 95 \% \mathrm{Cl},-3.79$ to $-0.01 ; p=$ 0.05). The meta-analysis revealed that the recurrence rate (RR, $0.74 ; 95 \% \mathrm{Cl}, 0.32$ to 1.71 ;

\footnotetext{
Abbreviation: AEs, adverse events; CENTRAL, Cochrane Central Registry of Controlled Trials; ChiCTR: Chinese Clinical Trial Registry; CHM, Chinese herbal medicine; CNKI, China Network Knowledge Infrastructure; CQVIP, China Science and Technology Journal Database; DLQI, dermatology life quality index; IL-17, interleukin-17; IL-6, interleukin-6; IL-1 $\beta$, interleukin-1 $\beta$; IFN- $\gamma$, Interferon- $\gamma$; KC, keratinocytes; MeSH, medical subject headings; PASI, psoriasis area severity index; PASI-50/60/75/90, PASI score decreases more than 50\%/60\%/75\%/90\% from baseline; PRISMA, preferred reporting items for systematic review and meta-analyses; RCTs, randomized control trials; RER, recurrence rate; TNF- $\alpha$, tumor necrosis factor- $\alpha$; VAS, visual analog scale; VEGF, vascular endothelial growth factor.
} 
$\mathrm{p}=0.48$ ) and proportion of adverse events (RR, 1.36; $95 \% \mathrm{Cl}, 0.95$ to 1.93; $\mathrm{p}=0.09$ ) associated with using CHM were similar to those associated with using a placebo.

Conclusion: $\mathrm{CHM}$ appears safe and effective in the treatment of psoriasis and has a great positive impact on the DQLI of patients; however, CHM could not completely eliminate skin lesions, improve pruritus severity, and reduce the recurrence rate.

Keywords: Chinese herbal medicine, psoriasis, high-quality, randomized controlled trials, meta-analysis

\section{INTRODUCTION}

Psoriasis is an autoimmune disease characterized by excessive proliferation and abnormal epidermal differentiation at typical body sites, with the plaque type being the most common presentation. It is a chronic, recurrent, inflammatory skin disorder that presents with erythema, papules, and scales, which may be painful and itchy (Griffiths and Barker, 2007; Ramanunny et al., 2020). Approximately $0.51-11.43 \%$ of adults and $0-1.37 \%$ of children worldwide suffer from psoriasis (Michalek et al., 2017). It is not only a skin disease but has an impact on the patients' physical and psychological quality of life. Evidence shows an association of psoriasis with arthritis, inflammatory bowel disease (Oliveira et al., 2015), metabolic syndrome (Armstrong et al., 2013), cerebrovascular diseases (Tangtatco and Lara-Carrales, 2017), and mood disorders such as depression and anxiety (Kurd et al., 2010), all of which can be considered comorbidities of psoriasis.

The etiology and pathogenesis of psoriasis has not yet been fully elucidated. It may be related to genetic and environmental factors, and an abnormal immune response. Studies have shown that psoriasis is a true $\mathrm{T}$ cell-mediated disease characterized by infiltration of inflammatory cells and excessive proliferation and differentiation of epidermal keratinocytes (KC) (Lowes et al., 2007). In the pathogenesis of psoriasis, KC damage in the epidermis triggers local inflammation, enhances the chemotaxis of T cells and neutrophils, and leads to $\mathrm{KC}$ activation and vascular endothelial dysfunction. This stimulates the production of circulating inflammatory cytokines such as tumor necrosis factor- $\alpha$ (TNF- $\alpha$ ), interleukin-17 (IL-17), interleukin-6 (IL-6), interleukin-1 $\beta$ (IL-1 $\beta)$, interferon- $\gamma \quad($ IFN- $\gamma)$ and vascular endothelial growth factor (VEGF). As a result, mature psoriatic plaques develop by inducing epidermal hyperplasia, epidermal cell proliferation and leukocyte subset recruitment into the skin (Hawkes et al., 2017).

The choice of treatment for psoriasis depends on many factors including the degree of the disease, its impact on the patient's life, and the patient's perception of the disease. At present, the pharmacological treatment includes topical therapy such as emollients, vitamin $\mathrm{D}_{3}$ derivatives, retinoids, glucocorticoids, and oral therapy such as tretinoins, and immunosuppressants. Additionally, biological therapies are effective for patients with moderate-to-severe psoriasis (Ramanunny et al., 2020). However, most of the therapies used in psoriasis have side effects and are not appropriate for long-term use. Therefore, it is essential that psoriasis treatments remain effective with reduced side effects.
Chinese herbal medicine ( $\mathrm{CHM}$ ) provides a theoretical basis for the treatment of skin diseases and has considerable benefits and a low toxicity (Chen et al., 2018; Ru et al., 2019; Kuai et al., 2020; Li S. et al., 2020; Ru et al., 2020; Yan et al., 2020). The forms of traditional Chinese medicine include topical (cream, oil, emulsion, and ointment) and oral (powder, tablet, capsule, and soup) treatments (Dermatology Branch of Chinese Association of traditional Chinese Medicine, 2013). The syndromes of psoriasis include: 1) blood-heat syndrome, seen in the progressive stage dominated by an inflammatory reaction; 2) blood stasis syndrome, seen in the quiescent stage dominated by hyperplasia of keratinocytes; 3) blood dryness syndrome, seen in the retrogressive stage characterized by skin barrier dysfunction; 4) blazing heat toxin syndrome, seen in the erythroderma or generalized pustule type; 5) damp-heat accumulation syndrome, seen in the localized pustular type; and 6) rheumatic obstruction syndrome, seen in the arthropathy type. All psoriasis syndromes can be transformed and show mixed characteristics between them. In terms of the therapeutic effect, CHM treatment can eliminate skin lesions by removing heat and cooling the blood, nourishing and activating the blood circulation and removing blood stasis, purging fire and providing a detoxification effect, clearing heat and dispelling dampness, dispelling wind and dredge collaterals (Psoriasis Professional Committee of Dermatology and venereology Branch of Chinese Medical Association, 2019).

Evidence from clinical studies suggests that CHMs could reduce the psoriasis area severity index (PASI) score and improve the dermatology life quality index (DLQI) of patients with psoriasis (Bahraini et al., 2018; Zheng et al., 2019). Pharmacological studies demonstrated that Tanshinone IIA, the effective component of danshen (Salvia miltiorrhiza), can inhibit the proliferation of $\mathrm{KC}$, induce apoptosis, and block the cell cycle of KC (Li F. L. et al., 2012). Drugs promoting blood circulation and removing blood stasis such as peach kernel and chuanxiong (Ligusticum chuanxiong Hort.) can dilate blood vessels, increase tissue blood flow, reduce blood viscosity, improve the microcirculation, and hence, promote the regression of skin lesions (Xiao et al., 2019). Additionally, several systematic reviews on the efficacy of CHM in the treatment of psoriasis have been published (Li N. et al., 2012; Deng et al., 2013; Yang et al., 2015; Zhang et al., 2015); however, most are low-quality studies. Moreover, a substantial amount of new data has been published. Therefore, the purpose of this quantitative study was to collect evidence on the efficacy and safety of CHM in the treatment of psoriasis to promote its clinical application. 


\section{METHODS}

This study was conducted in accordance with the Cochrane Handbook on Systematic Review of Interventions and presented in accordance with the Preferred Reporting Items for Systematic Review and Meta-Analysis (PRISMA) Guidelines (Liberati et al., 2009) (Additional file: Supplementary Table S1). Additionally, before starting the process, the review was registered in the PROSPERO database (CRD42020204557).

\section{Search Strategy}

We searched PubMed, Embase, Cochrane Central Register of Controlled Trials (CENTRAL), China Network Knowledge Infrastructure, China Science and Technology Journal Database, and Wan Fang Database from inception to May 31, 2020. We combined medical subject headings and free text words to retrieve all relevant studies. The following keywords were used: ("Psoriasis" OR "Psoriases" OR "Pustulosis Palmaris et Plantaris" OR "Palmoplantaris Pustulosis" OR "Pustulosis of Palms and Soles" OR "Palmoplantaris" OR "Pustulosis" OR "Pustular Psoriasis of Palms and Soles" OR "Parapsoriasis guttata") and ("Traditional Chinese Medicine” OR “Chung I Hsueh” OR "Hsueh, Chung I” OR "Traditional Medicine, Chinese" OR "Zhong Yi Xue" OR "Chinese Traditional Medicine" OR "Chinese Medicine, Traditional” OR "Chinese drugs" OR "Chinese herbal medicine" OR "Chinese herbal drug”) (Additional file: Supplementary Table S2). Moreover, we searched the Chinese Clinical Trial Registry (http://www.chictr.org.cn/index.aspx) and Clinical Trials (http:// www.clinicaltrials.gov) websites to identify protocols of high quality randomized controlled trials (RCTs).

\section{Inclusion and Exclusion Criteria}

The inclusion criteria were as follows: 1) patients presenting specific diagnostic criteria of psoriasis regardless of age, gender, or ethnicity; 2) RCTs that compared CHM with non-CHM interventions; 3) high-quality RCTs with a Jadad score $\geq 4$ in efficacy and safety analysis; and 4) trials must meet the criteria of double blindness. Studies were excluded if they met the following exclusion criteria: 1) participants with comorbidities; 2) different drug forms used in the experimental and control group; and 3) cointerventions that used anti-psoriatic drugs other than CHM.

\section{Data Extraction}

Three researchers (LK, YZ, and XD) carefully screened the qualified articles according to the predetermined inclusion and exclusion criteria. Two researchers (YL and JC) completed the self-designed data extraction form which included the name of the first author, year of publication, sample size, age and gender of participants, duration, intervention of experimental and control group, course of treatment, adverse events, and outcomes.

\section{Outcome Measures}

The primary outcome was an improvement of the PASI score after treatment, which is a quantitative rating score that measures the severity of psoriatic lesions based on area coverage and plaque appearance including scaling, infiltration, and erythema. The secondary outcomes included the efficiency, DLQI, visual analog scale (VAS) scores for the intensity of itching, recurrence rate, and adverse events (AEs).

\section{Risk of Bias in Individual Studies}

For each included study, two investigators (YL and YR) completed the Jadad scale used specifically for the quality of the evaluation method. A third-party researcher (MX) was consulted whenever there was a disagreement between the two investigators. Four dimensions of the Jadad scale (total seven points) were applied in this research, namely randomization, concealment, blind method, and reports of withdrawals and dropouts. Trials scoring 1-3 points were considered low quality and 4-7 as high quality.

\section{Statistical Analysis}

We synthesized the results in the meta-analysis using RevMan5.3 software provided by the Cochrane Collaboration. Risk ratios (RR) with 95\% confidence intervals (CI) were evaluated for dichotomous data, continuous data, mean difference (MD), and standard mean difference (SMD) were used. Across the trials, a fixed-effects model was used if there was homogeneity $\left(p>0.1, \mathrm{I}^{2}<50 \%\right)$; otherwise, a random-effect model was applied. $p$ values less than 0.05 were considered statistically significant.

\section{RESULTS}

\section{Included Studies}

We identified 3,943 studies after a preliminary search of six databases; 1,361 repetitive articles were excluded, and 1,699 articles were deleted after reading the titles and abstracts. Among the remaining 883 studies, 407 were excluded since 82 adopted acupuncture in the experimental group, 255 used alternate forms of medicine, 16 adopted single-component herb extracts, seven articles were protocols of RCTs, and 47 used CHM in the control group. Finally, the remaining 476 studies were evaluated using the Jadad scores. Eleven studies with a Jadad scale $\geq 4$ points met the inclusion criteria (Wang, 2003; Zhou, 2011; Zhou, 2012; Chen, 2016; Yao et al., 2016; Li et al., 2017; She, 2017; Lv, 2018; Zhang, 2018; Mao et al., 2019; Li B. Y. et al., 2020). Eight trials were published in Chinese and three in English. The flowchart was created to briefly illustrate the screening process (Figure 1).

\section{Study Characteristics}

A total of 1,215 patients participated in this study, including 711 in the experimental group and 504 in the control group. All 11 trials used a placebo as control while the forms of the intervention drugs were not identical. Four trials (Zhou, 2011; Zhou, 2012; Zhang, 2018; Mao et al., 2019) used decoctions, four (Yao et al., 2016; She, 2017; Lv, 2018; Zhang, 2018) used particles, one (Li et al., 2017) used ointments, and two (Wang, 2003; Li B. Y. et al., 2020) used capsules. Meanwhile, the treatment course ranged from 4 to 12 weeks.

PASI scores were recorded as the main outcome in all 11 trials: eight reported detailed scores (Wang, 2003; Zhou, 2011; Zhou, 2012; Li et al., 2017; She, 2017; Lv, 2018; Zhang, 2018; Mao et al., 2019), 5 (Chen, 2016; Yao et al., 2016; Li et al., 2017; Lv, 2018; Zhang, 2018) reported the number of patients who achieved PASI-50, 1 (Chen, 2016) reported on PASI-60, 4 (Chen, 2016; Lv, 


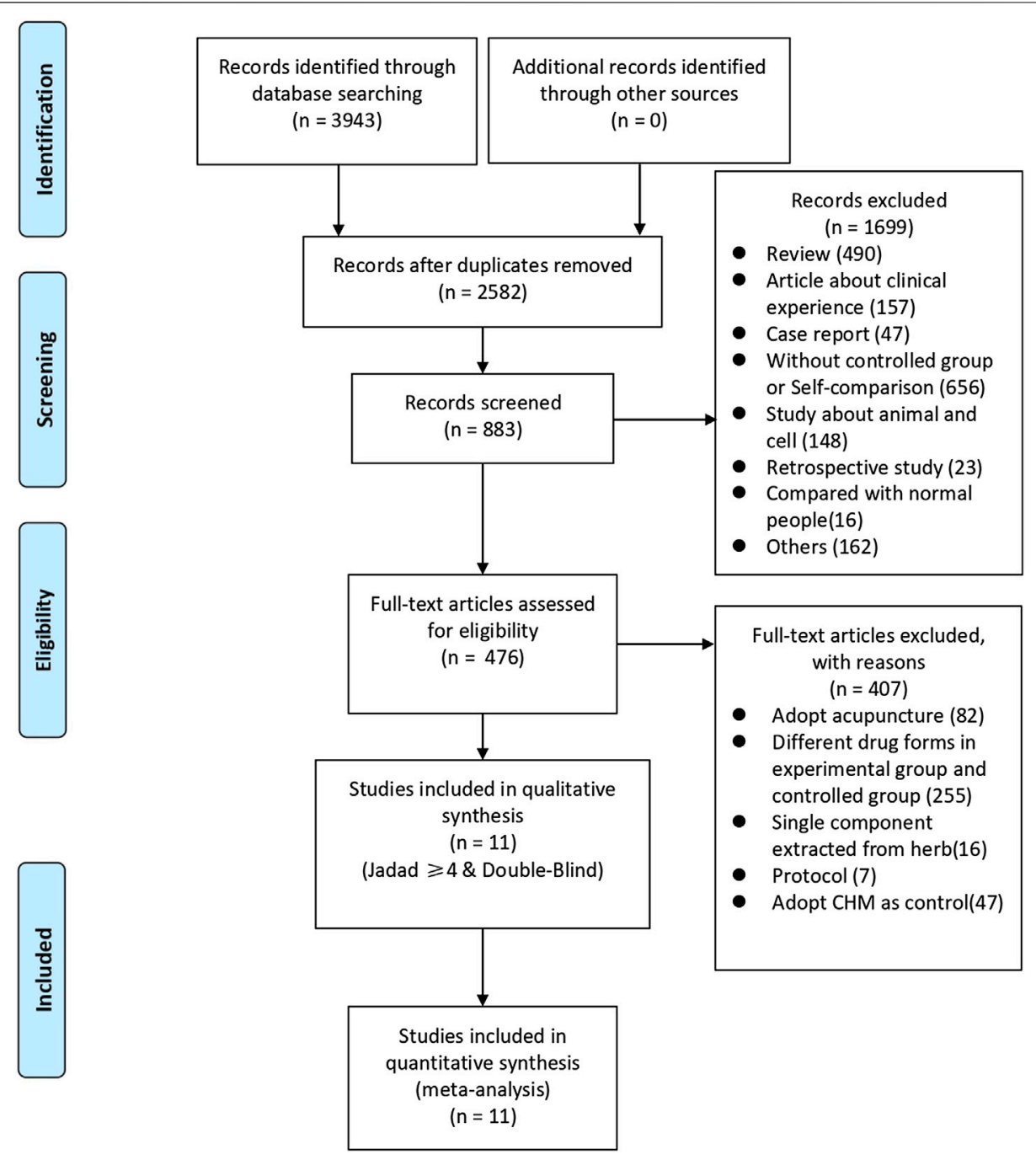

FIGURE 1 | Flowchart of search strategy and study selection, according to the Preferred Reporting Items for Systematic Reviews and Meta-analyses (PRISMA) guidelines.

2018; Zhang, 2018; Li B. Y. et al., 2020) reported on PASI-75, and 2 (Zhang, 2018; Li B. Y. et al., 2020) reported on PASI-90, which signify a PASI score reduction of at least $50,60,75,90 \%$. Three trials (Zhou, 2011; Zhou, 2012; She, 2017) assessed the efficacy rate, three (Zhou, 2012; Lv, 2018; Zhang, 2018) measured DLQI scores, and three reported VAS scores. Only three articles (Yao et al., 2016; Lv, 2018; Mao et al., 2019) calculated the recurrence rates. In terms of safety, adverse events were recorded in all trials. A summary table of preparations and the species or concentration of included CHMs was presented in Table 1.

\section{Description of the Chinese Herbal Medicines}

Fifty-four herbs were included in the 11 studies. The top eight most frequently used herbs were used more than 5 times and included the following: Rhizoma Smilacis Glabrae (rhizome of
Smilax glabra Roxb), Radix Paeoniae Rubra (root of Paeonia veitchii Lynch), Rhizoma Curcumae Aeruginosae [rhizome of Curcuma zedoaria (Christm.) Roscoe], Radix Salviae Miltiorrhizae (root and rhizome of Salvia miltiorrhiza Bunge), Radix Rehmanniae [root of Rehmannia glutinosa (Gaertn.) DC], Caulis Spatholobi (dried lianoid stem of Spatholobus suberectus Dunn), Radix Arnebiae (root of Lithospermum erythrorhizon Sieb. et Zucc.), Chinese angelica [root of Angelica sinensis (Oliv.) Diels.] (Additional File: Supplementary Table S3).

\section{Risk of Bias}

The methodological quality of each study was assessed with the Jadad score and all the included trials appeared to be of high quality, with a Jadad score between 4 and 7. Two trials failed (Wang, 2003; Mao et al., 2019) to report the concealment method, one trial (Li B. Y. et al., 2020) used a randomized method based on 
TABLE 1 | Summary of the characteristics of the included trails.

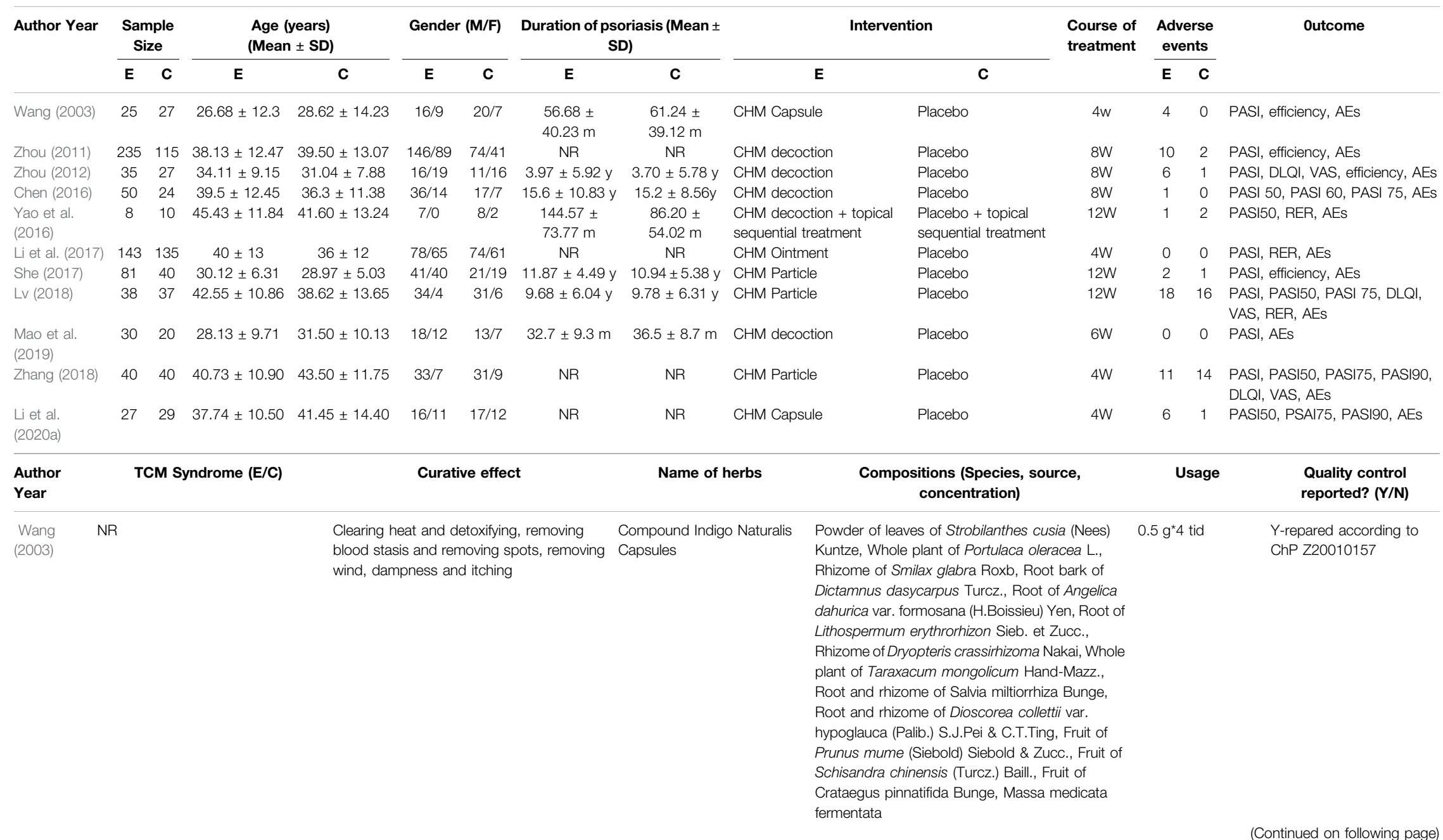


TABLE 1 | (Continued) Summary of the characteristics of the included trails.

\section{Author TCM Syndrome (E/C) Curative effect

Cooling Blood and

Blood dryness syndrome (79/38)

Nourishing blood and detoxification

Blood stasis syndrome (78/38)

Promoting blood circulation and

detoxification
Cooling blood and promoting blood circulation detoxification decoction

Rhizome of Smilax glabra Roxb 30g, Flower of $100 \mathrm{ml}$ bid

Sophora japonica L. $15 \mathrm{~g}$, Root of

Lithospermum erythrorhizon Sieb. et Zucc.

$10 \mathrm{~g}$, Rhizome of Paris polyphylla $9 \mathrm{~g}$, Root of Rehmannia glutinosa (Gaertn.) DC. 15g, Roo bark of Dictamnus dasycarpus Turcz. 10g, Root of Paeonia veitchii Lynch 10g, [Pharmacy Department of Beijing Hospital of traditional Chinese Medicine]

Nourishing Blood and

(15g, Root of Angelica sinensis 15g, Root of Angelica sinensis (Oliv.) Diels. 15g Root of Rehmannia glutinosa (Gaertn.) DC. $15 \mathrm{~g}$ Root of Ophiopogon japonicus (L. f.) Ker-Gawl.

$10 \mathrm{~g}$, Root of Scrophularia ningpoensis Hemsl.

$15 \mathrm{~g}$, dried lianoid stem of Spatholobus suberectus Dunn 15g, Rhizome of Smilax glabra Roxb 30g, [Pharmacy Department of Beijing Hospital of Traditional Chinese Medicine]

Promoting Blood Circulation Whole grass of Hedyotis diffusa Willd. 30g, and detoxification decoction Rhizome of Curcuma zedoaria (Christm.)

Roscoe 10g, Wing-shaped cork of Euonymus alatus (Thunb.) Siebold 10g, Flower of

Carthamus tinctorius L. 10g, dried lianoid stem of Spatholobus suberectus Dunn 30g, Kernel o Amygdalus persica L. 10g, Root and rhizome of Salvia miltiorrhiza Bunge 15g, [Pharmacy

Department of Beijing Hospital of traditional Chinese Medicine]

Liangxuehuoxue Complex

Leaf of Isatis tinctoria L. 15g, Root of Rehmannia $100 \mathrm{ml}$ bid glutinosa (Gaertn.) DC. 30g, Root of Scutellaria baicalensis Georgi 12g, Root of Lithospermum erythrorhizon Sieb. et Zucc. 9g, Root and rhizome of Salvia miltiorrhiza Bunge 12g, Root of Paeonia veitchii Lynch 6g, Root bark of Paeonia

suffruticosa Andr. 9g, Root of Angelica sinensis (Oliv.) Diels. 12g, Rhizome of Smilax glabra Roxb $30 \mathrm{~g}$

\section{Prescription}

\section{Quality control} reported? ( $\mathrm{Y} / \mathrm{N})$

Y- Prepared according to ChP; Hospital preparation

\section{$100 \mathrm{ml}$ bid}

$100 \mathrm{ml} \mathrm{bid}$ 
TABLE 1 | (Continued) Summary of the characteristics of the included trails.

\begin{tabular}{|c|c|c|c|c|c|c|}
\hline $\begin{array}{l}\text { Author } \\
\text { Year }\end{array}$ & TCM Syndrome (E/C) & Curative effect & Name of herbs & $\begin{array}{c}\text { Compositions (Species, source, } \\
\text { concentration) }\end{array}$ & Usage & $\begin{array}{l}\text { Quality control } \\
\text { reported? }(\mathrm{Y} / \mathrm{N})\end{array}$ \\
\hline \multirow[t]{3}{*}{$\begin{array}{l}\text { Chen } \\
(2016)\end{array}$} & Blood heat syndrome $(15 / 10)$ & Cooling blood and detoxification & $\begin{array}{l}\text { Cooling Blood and } \\
\text { detoxification decoction }\end{array}$ & $\begin{array}{l}\text { Rhizome of Smilax glabra Roxb, Flower of } \\
\text { Sophora japonica L., Root of Lithospermum } \\
\text { erythrorhizon Sieb. et Zucc., Root of Rehmannia } \\
\text { glutinosa (Gaertn.) DC., Root of Paeonia veitchii } \\
\text { Lynch, Root bark of Paeonia suffruticosa Andr., } \\
\text { Rhizome of Imperata cylindrica (L.) Beauv., Root } \\
\text { bark of Dictamnus dasycarpus Turcz., Root of } \\
\text { Saposhnikovia divaricata (Turcz. ex Ledeb.) } \\
\text { Schischk., Whole grass of Hedyotis diffusa Willd., } \\
\text { Rhizome of Paris polyphylla, Root of Isatis tinctoria } \\
\text { L., [Beijing Institute of traditional Chinese Medicine] }\end{array}$ & $200 \mathrm{ml}$ & $\begin{array}{l}\text { Y- Prepared according to } \\
\text { ChP; Hospital preparation }\end{array}$ \\
\hline & Blood dryness syndrome (17/5) & Nourishing blood and detoxification & $\begin{array}{l}\text { Nourishing Blood and } \\
\text { detoxification decoction }\end{array}$ & $\begin{array}{l}\text { Root of Angelica sinensis (Oliv.) Diels., Root of } \\
\text { Rehmannia glutinosa (Gaertn.) DC., Root and } \\
\text { rhizome of Salvia miltiorrhiza Bunge, dried lianoid } \\
\text { stem of Spatholobus suberectus Dunn, Root of } \\
\text { Ophiopogon japonicus (L. f.) Ker-Gawl., Root of } \\
\text { Scrophularia ningpoensis Hemsl., Root of } \\
\text { Trichosanthes kirilowii Maxim., Rhizome of Smilax } \\
\text { glabra Roxb, Whole grass of Hedyotis diffusa } \\
\text { Willd., Rhizome of Paris polyphylla, Rhizome of } \\
\text { Atractylodes lancea (Thunb.) DC., Fruit of Tribulus } \\
\text { terrestris L., [Beijing Institute of traditional Chinese } \\
\text { Medicine] }\end{array}$ & $200 \mathrm{ml}$ & \\
\hline & Blood stasis syndrome (4/3) & $\begin{array}{l}\text { Promoting blood circulation and } \\
\text { detoxification }\end{array}$ & $\begin{array}{l}\text { Promoting Blood Circulation } \\
\text { and detoxification decoction }\end{array}$ & $\begin{array}{l}\text { Root of Angelica sinensis (Oliv.) Diels., Rhizome of } \\
\text { Curcuma zedoaria (Christm.) Roscoe, Root and } \\
\text { rhizome of Salvia miltiorrhiza Bunge dried lianoid } \\
\text { stem of Spatholobus suberectus Dunn, Kernel of } \\
\text { Amygdalus persica L., Root of Scrophularia } \\
\text { ningpoensis Hemsl., Root and rhizome of Clematis } \\
\text { chinensis Osbeck, Branch of Cinnamomum cassia } \\
\text { (L.) J. Presl, Rhizome of Atractylodes lancea } \\
\text { (Thunb.) DC., Wing-shaped cork of Euonymus } \\
\text { alatus (Thunb.) Siebold, Whole grass of Hedyotis } \\
\text { diffusa Willd., Rhizome of Paris polyphylla [Beijing } \\
\text { Institute of traditional Chinese Medicine] }\end{array}$ & $200 \mathrm{ml}$ & \\
\hline $\begin{array}{l}\text { Yao et al. } \\
\text { (2016) }\end{array}$ & NR & $\begin{array}{l}\text { Promoting blood circulation, removing } \\
\text { blood stasis and removing spots, removing } \\
\text { wind, dampness and itching }\end{array}$ & PSORI-CM01 & $\begin{array}{l}\text { Root of Paeonia veitchii Lynch, Rhizome of } \\
\text { Curcuma zedoaria (Christm.) Roscoe, Whole plant } \\
\text { of Sarcandra glabra (Thunb.) Nakai, Root and } \\
\text { rhizome of Glycyrrhiza uralensis Fisch. ex DC., } \\
\text { Fruit of Prunus mume (Siebold) Siebold \& Zucc., } \\
\text { Root of Lithospermum erythrorhizon Sieb. et } \\
\text { Zucc., and Rhizome of Smilax glabra Roxb, } \\
\text { [Pharmaceutical department of Chinese herbal } \\
\text { medicine of GPHCM] }\end{array}$ & $100 \mathrm{ml} \mathrm{bid}$ & $\begin{array}{l}\text { Y- Prepared according to } \\
\text { ChP; Hospital preparation }\end{array}$ \\
\hline $\begin{array}{l}\text { Li et al. } \\
\text { (2017) }\end{array}$ & Blood heat syndrome (143/135) & $\begin{array}{l}\text { Clearing excess heat and dampness, and } \\
\text { relieving swelling and pain. }\end{array}$ & Pulian Ointment & $\begin{array}{l}\text { Powder of bark of Phellodendron amurense Rupr. } \\
50 \mathrm{~g} \text {, Powder of root of Scutellaria baicalensis } \\
\text { Georgi } 50 \mathrm{~g} \text { and white petroleum jelly } 400 \mathrm{~g} \text {, } \\
\text { [China-Japan Friendship Hospital] }\end{array}$ & $\begin{array}{l}2 \mathrm{~mm} \text { larger than } \\
\text { the skin lesion area } \\
\text { bid }\end{array}$ & $\begin{array}{l}\text { Y- Prepared according to } \\
\text { ChP; Hospital preparation }\end{array}$ \\
\hline
\end{tabular}


TABLE 1 | (Continued) Summary of the characteristics of the included trails.

Author TCM Syndrome (E/C) Curative effect

Year

She Blood dryness syndrome (44/20)
Calming the mind and relieving itching

(Blood dryness)

Calming the mind and relieving itching (Blood stasis)

No.2 Calm-the-Mind-andRelieve-Itching Formula

Blood stasis syndrome (37/20)
No.1 Calm-the-Mind-and-

Relieve-Itching Formula

\section{Name of herbs}

PSORI-CMO2
Cooling blood and promoting blood circulation

\section{Compositions (Species, source,}

concentration)

\section{Usage}

Calcined Dragon Bone 30g, Calcined Concha

Osterae (Ostrea gigas Thunberg) 30g Concha

Margaritifear (Pteria martensii (Dunker)) 30g.

Calcined Magentitum $30 \mathrm{~g}$, Petiole charcoal of

Trachycarpus fortunei (Hook). H. Wendi. 30g,

Root charcoal of Sanguisorba officinalis L. 30g,

Root of Angelica sinensis (Oliv.) Diels. 10g,

Processing Root of Rehmannia glutinosa (Gaertn.)

DC.10g, [Beijing Tcmages Pharmaceutical Co.,

LTD]

Calcined Dragon Bone 30g, Calcined Concha Osterae (Ostrea gigas Thunberg) 30g, Concha Margaritifear (Pteria martensii (Dunker)) 30g,

Calcined Magentitum 30g, Petiole charcoal of Trachycarpus fortunei (Hook). H. Wendi. 30g,

Root charcoal of Sanguisorba officinalis L. 30g, Rhizome of Sparganium stoloniferum (Graebn.) Buch-Ham. 10g, Rhizome of Curcuma zedoaria (Christm.) Roscoe 10g, [Beijing Tcmages

Pharmaceutical Co., LTD]

Rhizome of Curcuma zedoaria (Christm.) Roscoe, 1 pack bid

Root of Paeonia veitchii Lynch, Rhizome of Smilax glabra Roxb, Whole plant of Sarcandra glabra

(Thunb.) Nakai, Fruit of Prunus mume (Siebold) Siebold \& Zucc.

Mao et al. Blood heat syndrome (30/20) (2019)

Zhang Blood heat syndrome (3/4) Blood

(2018) stasis syndrome (0/1) Blood dryness syndrome $(37 / 35)$

Promoting blood circulation, removing blood stasis and removing spots, removing

Liang xue huo xue decoction $(\mathrm{XHXD})$

Flower of Sophora japonica L. $30 \mathrm{~g}$, Root and

rhizome of Salvia miltiorrhiza Bunge 15 g Rhizome

of Imperata cyln

Lithospermum erythrorhizon Sieb. et Zucc. $15 \mathrm{~g}$

Root of Paeonia veitchii Lynch $15 \mathrm{~g}$, and dried

lianoid stem of Spatholobus suberectus Dunn

$30 \mathrm{~g}$.

Root of Paeonia veitchii Lynch, Rhizome of

$5.5 \mathrm{~g}$ bid

Curcuma zedoaria (Christm.) Roscoe, Whole plant

of Sarcandra glabra (Thunb.) Nakai, Root and

rhizome of Glycyrrhiza uralensis Fisch. ex DC, Fruit

of Prunus mume (Siebold) Siebold \& Zucc., Root of

Lithospermum erythrorhizon Sieb. et Zucc.,

Rhizome of Smilax glabra Roxb, [Jiangyin Tianjiang

Pharmaceutical Co., Ltd]

Tripterygium hypoglaucum (Levl.) Hutch, Leaf of $0.3 \mathrm{~g}$ 22\# tid
Epimedium brevicornum Maxim., Fruit of Lycium
barbarum L, Seed of Cuscuta chinensis Lam.
[Guangzhou chenliji Pharmaceutical Co., Ltd]
(2020a)
tonifying the kidney and removing
obstruction in the channels on the blood
Kunxian capsule

$\begin{array}{ll}200 \mathrm{ml} \text { bid } & \text { Y- Prepared according to } \\ \text { ChP; Pharmacy } \\ \text { preparation }\end{array}$

$200 \mathrm{ml}$ bid

pack bid

NR

NR

Y - Prepared according to
ChP; Pharmacy

preparation

$Y$ - Prepared according to ChP YBZ07522006

C, control group; E, experimental group; NR, no report; AEs, adverse events; RER, recurrence rate; DLQI, dermatology life quality index; VAS, visual analog scale; M, Male; F, Female; $w$, weeks; $m$, months; $y$, years.
ChP, Pharmacopoeia of the People's Republic of China; GPHCM, Guangdong Provincial Hospital of Chinese Medicine; NR, Not Remined; bid, bis in die; tid, ter in die; YBZO7522006, State food and drug administration of the People's ChP, Pharmacopoeia of the People's Republic or 
TABLE 2 | Jadad scale of the included trials.

\begin{tabular}{llllll}
\hline \multirow{2}{*}{ Author Year } & \multicolumn{5}{c}{ Jadad Scale } \\
\cline { 2 - 6 } & a & b & c & d & T \\
\hline Wang (2003) & 1 & 0 & 2 & 1 & 4 \\
Zhou (2011) & 2 & 2 & 2 & 1 & 7 \\
Zhou (2012) & 2 & 2 & 2 & 1 & 7 \\
Chen (2016) & 2 & 2 & 2 & 1 & 7 \\
Yao et al. (2016) & 2 & 2 & 2 & 1 & 7 \\
Li et al. (2017) & 2 & 2 & 2 & 1 & 7 \\
She (2017) & 2 & 2 & 2 & 1 & 7 \\
Lv (2018) & 2 & 2 & 2 & 1 & 7 \\
Mao et al. (2019) & 1 & 1 & 2 & 1 & 5 \\
Zhang (2018) & 2 & 2 & 2 & 1 & 7 \\
Li B. Y. et al. (2020) & 1 & 2 & 2 & 1 & 6
\end{tabular}

From a to d, dimension of the Jadad scale. Points awarded: a, study was described as randomized, 1 point; the method was appropriate (table of random numbers, computer generated, etc.), 2 points; $b$, study used allocation concealment, 1 point; the method was appropriate (taken by the third one who wasn't researcher or patient, opaque envelope, etc.), 2 points; c, study was described as double blind, 1 point; the method was appropriate (identical placebo, active placebo, dummy, etc.), 2 points; $d$, study reported withdraws and dropouts and described the reasons. $T$, total.

the order of patients' visits, two trials (Wang, 2003; Mao et al., 2019) did not describe the method of randomization. More details are shown in Table 2.

\section{PRIMARY OUTCOMES}

\section{PASI Score}

We conducted a comprehensive analysis of the PASI scores recorded in eight trials. The PASI score of the CHM group was significantly lower than that of the placebo group after treatment $(\mathrm{MD},-4.02 ; 95 \% \mathrm{CI},-6.71$ to $-1.34 ; p=0.003$ ) (Figure 2). Additionally, we performed a subgroup analysis based on different PASI reduction indices. For PASI-50 and PASI-90, there were no statistically significant result (PASI-50: RR, 1.53 ; 95\% CI, 0.78 to $3.01 ; p=0.21$; PASI-90: RR, $3.01 ; 95 \%$ CI, 0.32 to $28.56 ; p=0.34)$. Meanwhile, to achieve PASI- 60 and
PASI-75, the arrival rate of the CHM group was higher than that of the placebo group (PASI-60: RR, 3.52; 95\% CI, 1.17 to 10.61 ; $p=0.03$; PASI-75: RR, 9.87; 95\% CI, 3.11 to $31.31 ; p=0.0001$ ) (Figure 3).

\section{SECONDARY OUTCOME}

\section{Efficacy Rate}

The efficacy rate was higher in patients receiving $\mathrm{CHM}$ than those receiving placebo (RR, 1.72; 95\% CI, 1.01 to $2.93 ; p=0.04$ ) (Figure 4).

\section{Dermatology Life Quality Index}

Three trials applied the DLQI to assess the quality of life of patients with psoriasis. The comprehensive results suggested a greater impact of CHM than placebo (MD, -2.12 ; 95\% CI, -3.75 to $-0.49 ; p=0.01$ ) (Figure 5).

\section{Pruritus Severity}

The visual analogue scale (VAS) was performed to assess pruritus severity. Our meta-analysis indicated that there was no significant difference between the CHM group and the control group (MD, $-1.90 ; 95 \% \mathrm{CI},-3.79$ to $-0.01 ; p=0.05$ ) (Figure 6).

\section{Recurrence Rate}

Only three trials (Yao et al., 2016; Li et al., 2017; Lv, 2018) included follow-up surveys and assessed recurrence rate. The meta-analysis revealed that the recurrence rate associated with $\mathrm{CHM}$ was similar that with a placebo (RR, $0.74 ; 95 \% \mathrm{CI}, 0.32$ to $1.71 ; p=0.48)$ (Figure 7).

\section{Safety}

All trials assessed AEs including infection, gastrointestinal discomfort, abnormal liver function, limb erythema, and burning heat sensation. Meta-analysis results showed that the incidence of AEs in patients treated with CHM was similar to that of the placebo (RR, 1.36; 95\% CI, 0.95 to $1.93 ; p=0.09$ ) (Figure 8).

\begin{tabular}{|c|c|c|c|c|c|c|c|c|c|c|}
\hline \multirow[b]{2}{*}{ Studv or Subgroup } & \multicolumn{3}{|c|}{ CHM } & \multicolumn{3}{|c|}{ Placebo } & \multicolumn{3}{|c|}{ Mean Difference } & \multirow{2}{*}{$\begin{array}{l}\text { Mean Difference } \\
\text { IV.Random. } 95 \% \mathrm{Cl}\end{array}$} \\
\hline & Mean & SD & Total & Mean & SD & Total & Weight & IV, Random, $95 \% \mathrm{C}$ & I Year & \\
\hline Wang 2003 & 2.12 & 0.07 & 25 & 9.64 & 2.46 & 27 & $12.8 \%$ & $-7.52[-8.45,-6.59]$ & 2003 & $\Rightarrow$ \\
\hline Zhou 2011 & 6.69 & 6.53 & 235 & 7.06 & 7.57 & 115 & $12.4 \%$ & $-0.37[-1.99,1.25]$ & 2011 & \\
\hline Zhou 2012 & 3.8 & 2.87 & 35 & 8.7 & 2.17 & 27 & $12.7 \%$ & $-4.90[-6.15,-3.65]$ & 2012 & - \\
\hline Li 2017 & 4.239 & 3.4265 & 147 & 4.974 & 5.232 & 135 & $12.8 \%$ & $-0.74[-1.78,0.31]$ & 2017 & \\
\hline She 2017 & 11.34 & 6.58 & 81 & 26.68 & 7.12 & 40 & $11.6 \%$ & $-15.34[-17.97,-12.71]$ & 2017 & $\longleftarrow$ \\
\hline LV 2018 & 5.9 & 2.7 & 30 & 7.9 & 3 & 20 & $12.4 \%$ & $-2.00[-3.63,-0.37]$ & 2018 & \\
\hline Mao 2019 & 4.51 & 2.97 & 38 & 4.37 & 2.2 & 37 & $12.7 \%$ & $0.14[-1.04,1.32]$ & 2018 & \\
\hline Zhang 2018 & 4.13 & 2.97 & 40 & 6.46 & 2.87 & 40 & $12.6 \%$ & $-2.33[-3.61,-1.05]$ & 2019 & - \\
\hline Total $(95 \%$ CI $)$ & & & 631 & & & 441 & $100.0 \%$ & $-4.02[-6.71,-1.34]$ & & \\
\hline \multicolumn{10}{|c|}{$\begin{array}{l}\text { Heterogeneity: } \operatorname{Tau}^{2}=14.44 ; \mathrm{Chi}^{2}=238.94, \text { df }=7(P<0.00001) ; I^{2}=97 \% \\
\text { Test for owerall effect: } Z=2.94(P=0.003)\end{array}$} & $\begin{array}{lll}-10 & -5 & 0 \\
\text { Placebo } & & \\
\mathrm{CHM}\end{array}$ \\
\hline
\end{tabular}

FIGURE 2 | Forest plot of PASI Score between CHM and placebo groups. (CHM: Chinese Herbal Medicine; PASI: psoriasis area severity index). 


\begin{tabular}{|c|c|c|c|c|c|c|c|c|c|c|}
\hline Studv or Subgroup & $\begin{array}{l}\text { CHM } \\
\text { Events }\end{array}$ & Total & Placebo & Total & Weight & $\begin{array}{l}\text { Risk Ratio } \\
\text { M-H.Random. } 95 \% \mathrm{Cl} \text { Year }\end{array}$ & \multicolumn{4}{|c|}{$\begin{aligned} & \text { Risk Ratio } \\
& \text { M-H. Random. } 95 \% \mathrm{Cl}\end{aligned}$} \\
\hline \multicolumn{11}{|c|}{ 1.1.1 A chievement of PASI50 of CHM for Psoriasis } \\
\hline Yao 2016 & 6 & 7 & 9 & 10 & $14.4 \%$ & $0.95[0.66,1.37] 2016$ & & & 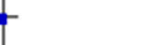 & \\
\hline Chen 2016 & 29 & 50 & 13 & 24 & $14.1 \%$ & $1.07[0.69,1.66] 2016$ & & & + & \\
\hline Lv 2018 & 10 & 38 & 6 & 37 & $11.9 \%$ & $1.62[0.66,4.01] 2018$ & & & & \\
\hline Zhang 2018 & 22 & 40 & 12 & 40 & $13.7 \%$ & $1.83[1.06,3.18] 2019$ & & & $\rightarrow$ & \\
\hline Li 2020 & 20 & 27 & 0 & 29 & $4.4 \%$ & $43.93[2.79,692.49] 2020$ & & & & \\
\hline Subtotal $(95 \% \mathrm{CI})$ & & 162 & & 140 & $58.6 \%$ & $1.53[0.78,3.01]$ & & & & \\
\hline Total events & 87 & & 40 & & & & & & & \\
\hline \multicolumn{11}{|c|}{$\begin{array}{l}\text { Heterogeneity: } \text { Tau }^{2}=0.41 ; \text { Chi }^{2}=22.64, d f=4(P=0.0001) ; I^{2}=82 \% \\
\text { Test for overall effect: } Z=1.25(P=0.21)\end{array}$} \\
\hline \multicolumn{11}{|c|}{ 1.1.2 Achievement of PASI60 of CHM for Psoriasis } \\
\hline Chen 2016 & 22 & 50 & 3 & 24 & $10.9 \%$ & $3.52[1.17,10.61] 2016$ & & & & \\
\hline Subtotal $(95 \% \mathrm{CI})$ & & 50 & & 24 & $10.9 \%$ & $3.52[1.17,10.61]$ & & & & \\
\hline Total events & 22 & & 3 & & & & & & & \\
\hline \multicolumn{11}{|c|}{ Heterogeneity: Not applicable } \\
\hline \multicolumn{11}{|c|}{ Test for overall effect: $Z=2.23(P=0.03)$} \\
\hline \multicolumn{11}{|c|}{ 1.1.3 A chievement of PASI75 of CHM for Psoriasis } \\
\hline Chen 2016 & 22 & 50 & 1 & 24 & $6.9 \%$ & $10.56[1.51,73.78] 2016$ & & & & \\
\hline Lv 2018 & 4 & 38 & 0 & 37 & $4.2 \%$ & $8.77[0.49,157.38] 2018$ & & & & \\
\hline Zhang 2018 & 7 & 40 & 1 & 40 & $6.5 \%$ & $7.00[0.90,54.32] 2019$ & & & & \\
\hline Li 2020 & 8 & 27 & 0 & 29 & $4.3 \%$ & $18.21[1.10,301.11] 2020$ & & & & \\
\hline Subtotal $(95 \% \mathrm{CI})$ & & 155 & & 130 & $21.9 \%$ & $9.87[3.11,31.31]$ & & & & \\
\hline Total events & 41 & & 2 & & & & & & & \\
\hline \multicolumn{11}{|c|}{$\begin{array}{l}\text { Heterogeneity: } \text { Tau }^{2}=0.00 ; \mathrm{Chi}^{2}=0.31, \mathrm{df}=3(\mathrm{P}=0.96) ; \mathrm{I}^{2}=0 \% \\
\text { Test for overall effect: } Z=3.89(\mathrm{P}=0.0001)\end{array}$} \\
\hline \multicolumn{11}{|c|}{ 1.1.4 A chievement of PASI90 of CHM for Psoriasis } \\
\hline Zhang 2018 & 1 & 33 & 1 & 34 & $4.5 \%$ & $1.03[0.07,15.80] 2019$ & & & & \\
\hline Li 2020 & 4 & 27 & 0 & 29 & $4.2 \%$ & $9.64[0.54,171.09] 2020$ & & & & \\
\hline Subtotal $(95 \% \mathrm{CI})$ & & 60 & & 63 & $8.7 \%$ & $3.01[0.32,28.56]$ & & & & \\
\hline Total events & 5 & & 1 & & & & & & & \\
\hline \multicolumn{11}{|c|}{$\begin{array}{l}\text { Heterogeneity: } \operatorname{Tau}^{2}=0.59 ; \mathrm{Chi}^{2}=1.29, \mathrm{df}=1(\mathrm{P}=0.26) ; \mathrm{I}^{2}=22 \% \\
\text { Test for overall effect: } Z=0.96(\mathrm{P}=0.34)\end{array}$} \\
\hline Total $(95 \% \mathrm{Cl})$ & & 427 & & 357 & $100.0 \%$ & $2.85[1.43,5.71]$ & & & & \\
\hline Total events & 155 & & 46 & & & & & & & \\
\hline \multicolumn{7}{|c|}{$\begin{array}{l}\text { Heterogeneity: } \operatorname{Tau}^{2}=0.83 ; \mathrm{Chi}^{2}=56.33, \mathrm{df}=11(\mathrm{P}<0.00001) ; \mathrm{I}^{2}=80 \% \\
\text { Test for overall effect: } Z=2.97(P=0.003) \\
\text { Test for subaroun differences: } \mathrm{Chi}^{2}=7.78 . \mathrm{df}=3(\mathrm{P}=0.05) . \mathrm{I}^{2}=61.4 \%\end{array}$} & 0.01 & $\begin{array}{c}0.1 \\
\text { Plecebo }\end{array}$ & $\mathrm{CHM}^{10}$ & 100 \\
\hline
\end{tabular}

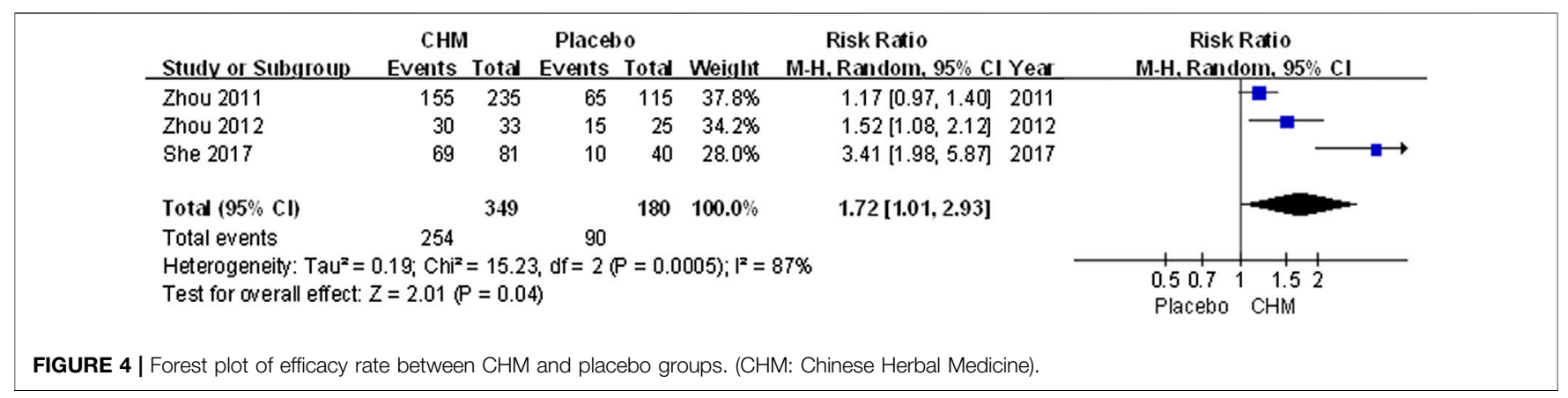




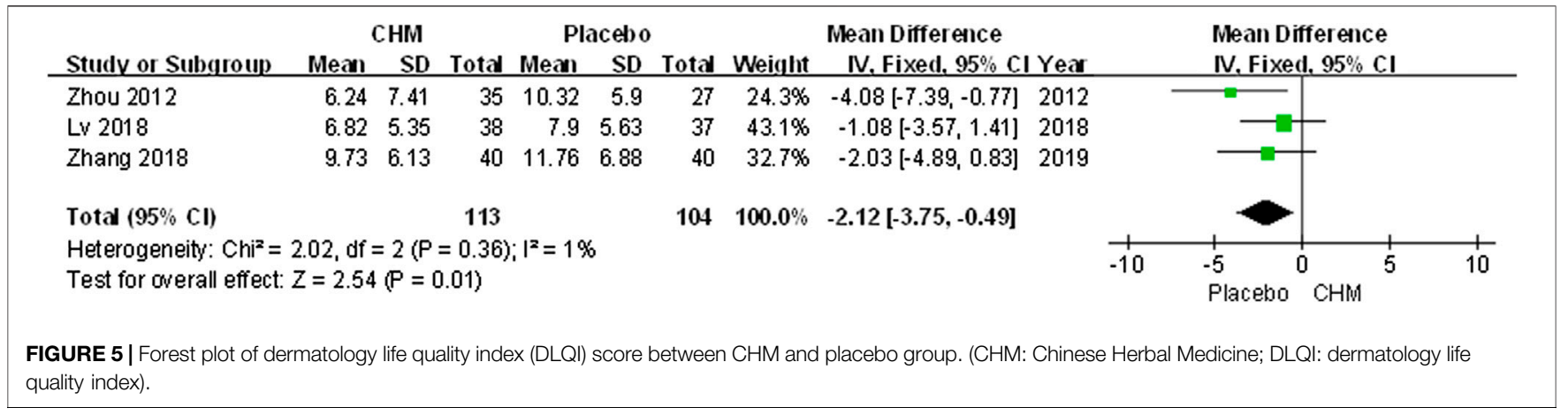

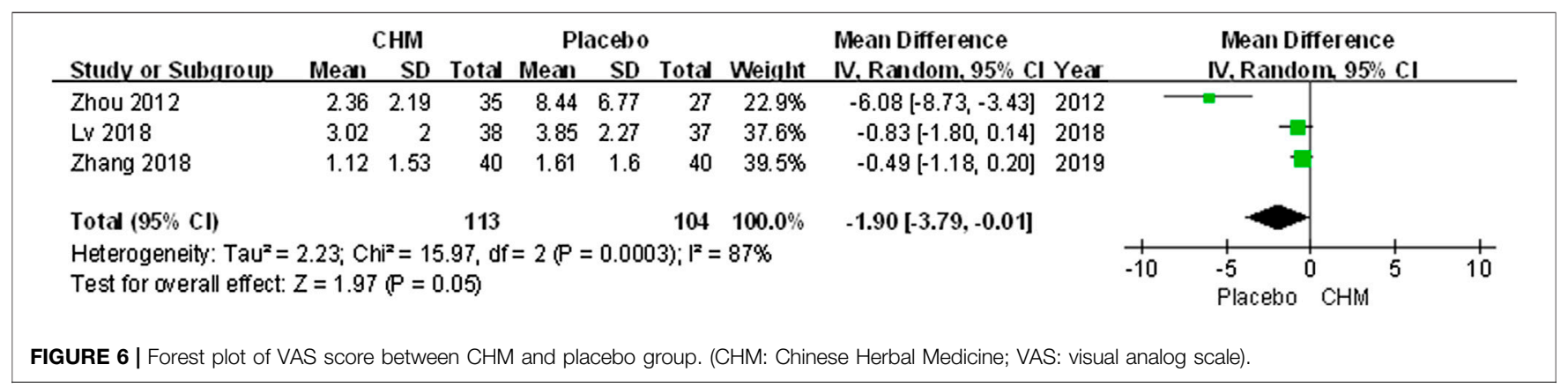

\begin{tabular}{|c|c|c|c|c|c|c|c|c|c|c|c|c|}
\hline & Studv or Subaroup & $\begin{array}{l}\text { CHM } \\
\text { Events } \\
\end{array}$ & Total & $\begin{array}{l}\text { Placel } \\
\text { Events }\end{array}$ & Total & Weight & $\begin{array}{l}\text { Risk Ratio } \\
\text { M-H, Fixed. 95\% Cl Year }\end{array}$ & & $\begin{array}{r}\text { Risk R } \\
\text { ML-H, Fixe }\end{array}$ & $\begin{array}{l}\text { Ratio } \\
\text { ed. } 95 \%\end{array}$ & & \\
\hline & Yao 2016 & 1 & 7 & 6 & 10 & $40.7 \%$ & $0.24[0.04,1.57] 2016$ & & & T & & \\
\hline & Li 2017 & 4 & 143 & 6 & 135 & $50.9 \%$ & $0.63[0.18,2.18] 2017$ & & - & - & & \\
\hline & LV 2018 & 4 & 38 & 1 & 37 & $8.4 \%$ & $3.89[0.46,33.24] 2018$ & & & & & \\
\hline & Total $(95 \% \mathrm{Cl})$ & & 188 & & 182 & $100.0 \%$ & $0.74[0.32,1.71]$ & & & & & \\
\hline & Total events & 9 & & 13 & & & & & & & & \\
\hline & $\begin{array}{l}\text { Heterogeneity: } \mathrm{Chi}^{2}= \\
\text { Test for overall effect: }\end{array}$ & $\begin{array}{l}3.76, d f=2 \\
Z=0.70(F\end{array}$ & $\begin{array}{l}2(P=0 \\
P=0.48\end{array}$ & $\begin{array}{l}0.15) ; 1^{2}= \\
\text { 8) }\end{array}$ & $47 \%$ & & & $\frac{1}{0.02}$ & $\begin{array}{ll}1 & 1 \\
\text { Placebo } & 1\end{array}$ & $1 \mathrm{CHM}$ & 10 & 50 \\
\hline
\end{tabular}

\section{DISCUSSION}

This systematic review involved 11 randomized controlled trials that evaluated the efficacy and safety of CHM therapy in the treatment of psoriasis. The comprehensive results showed that the PASI score of the CHM group was significantly lower than of the placebo group, while the efficacy rate was higher in the $\mathrm{CHM}$ group than in the placebo group. To achieve PASI-50 and PASI-90, the arrival rate of the CHM group was similar to that of the placebo group; however, it was significantly improved for PASI-60 and PASI-75. The results suggested that there may be limited cure of the skin lesions. Indeed, the Chinese guidelines for the diagnosis and treatment of psoriasis (2018 version) pointed out that patients with mild-to-moderate psoriasis are mainly treated with internal CHM treatment, while the severe, pustular, erythrodermic, and arthropathic psoriasis types should be treated with integrated traditional Chinese and western medicine (Psoriasis Professional Committee of Dermatology and venereology Branch of Chinese Medical Association, 2019).
Furthermore, the comprehensive results suggested a greater impact of CHM on the DLQI of patients. On the contrary, there is currently no evidence regarding the efficacy of CHM in reducing episodes of psoriasis relapse and relief pruritus severity. In terms of safety, there was no significant difference between the CHM group and the control group, which indicated that $\mathrm{CHM}$ can be safely used for psoriasis.

Psoriasis is a chronic, relapsing skin disease that has psychological and physical effects and substantially impacts the quality of life of patients (Zandi et al., 2011). The most common approach to measure the health-related quality of life (QOL) is psychometric instruments, which measure QOL in many fields; reason why the DLQI is used in dermatology. Our results suggested that the clearance of skin damage by traditional Chinese medicine is effective and safe, and is closely related to improving the quality of life of patients. In addition, the integration of CHM and western medicine has been proven effective. It is known that the treatment of psoriasis in 


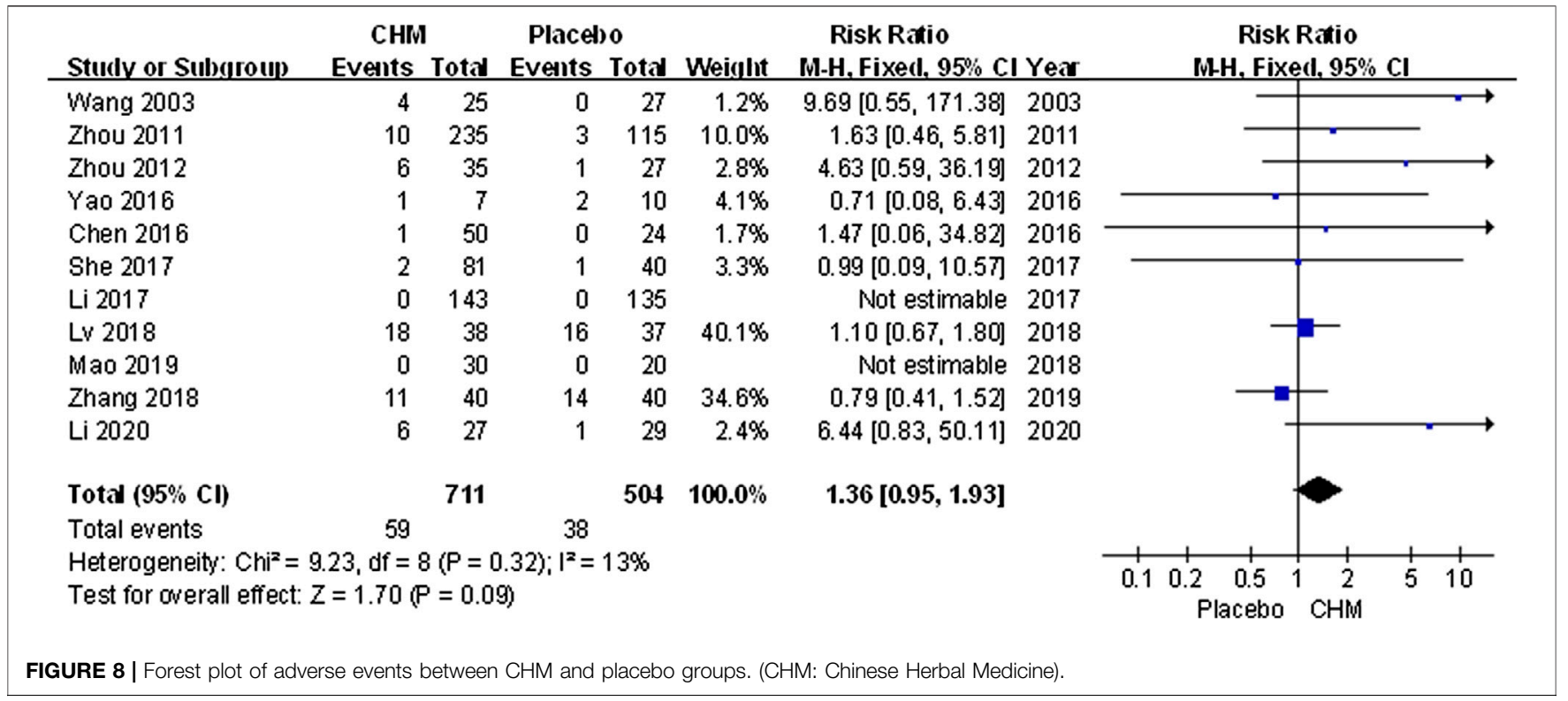

TABLE 3 | Chinese Herbal Medicine for Psoriasis in clinical development.

Title

Oral chinese herbal medicine for Psoriasis

Vulgaris with blood heat syndrome

YXBCM01(PSORI-CM01) granules for psoriasis vulgaris: a Randomised double-blind,

double-dummy, controlled clinical study

Oral chinese herbal medicine for Psoriasis

Vulgaris with blood stasis syndrome

A clinical trial of topical application containing Plaque Psoriasis

Radix Rubiae for plaque-type psoriasis

Treatment of Kunxian capsule for moderate to Plaque Psoriasis

severe plaque psoriasis: a multi-center,

randomized, double-blinded, double-dummy,

positive-drug, parallel-controlled clinical trial

A randomized double-blind placebo parallel

control trial for Chinese herbal bath in the

treatment of psoriasis vulgaris (blood heat

syndrome)

A multicenter, randomized, double-blind,

placebo-controlled study based on cooling

blood latent Yang method combined with

biological agents on the impact in recurrence of

plaque psoriasis

A Randomized Controlled study on the Combined and sequential optimal plan of traditional chinese medicine internal and external therapy for Psoriasis

Oral Chinese herbal medicine (Guben Huayu

Formula) concurrent with methotrexate for

patients with moderate-to-severe psoriasis: a

Randomized controlled trial

psoriasis

Moderate to severe Psoriasis

$\begin{array}{lllll}\begin{array}{c}\text { Condition or } \\ \text { desease }\end{array} & \text { Intervention (E/C) } & \text { Status } & \text { Phase } & \text { Identifier } \\ \text { Psoriasis Vulgaris } & \text { Jueyin granules/Jueyin granules Placebo } & \text { Not yet recruiting } & \text { Phase } 2 & \text { NCT03961230 } \\ \text { Plaque Psoriasis } & \text { PSORI-CM01(YXBCM01) granule/placebo } & \text { Terminated } & \text { Not applicable } & \text { NCT02153840 }\end{array}$

Psoriasis Vulgaris Taodan Granules/Taodan granules Placebo

Topical application containing Radix

Rubiae/vehicle preparation

placebo/Kunxian Capsule placebo +

Not yet recruiting Phase 2

NCT03942198

Not yet recruiting Phase 1

ChiCTR-IPC-

15007019

Methotrexate tablets

Psoriasis vulgaris Basic treatment + Chinese herbal bath therapy/Basic treatment + Chinese herba placebo bath therapy

Plaque Psoriasis Izituzumab + JYKL (4 weeks) + JYKL (8 weeks)/lzituzumab + JYKL (4 weeks) + JYKL placebo (8 weeks)/lzituzumab + JYKL placebo (4 weeks) + JYKL (8 weeks)/ Izituzumab + JYKL placebo (4 weeks) + JYKL placebo (8 weeks)

Mild and Jueyin granules + moving cupping placebo Not yet recruiting Phase 4

ChiCTR2000035992

moderate plaque therapy/Jueyin granules placebo + moving cupping therapy

Gu ben hua yu fang plus methotrexate/
Chinese herbal medicine placebo plus

Recruiting

Not applicable ChiCTR2000035278 methotrexate combination with a local sequential therapy can be used to eliminate skin lesions, as well as to relieve itching faster and prolong the therapeutic effect (Yao et al., 2016). Coincidentally, patients who received both a traditional Chinese medicine bath and NB-UVB treatment had a longer remission period (Wang et al, 2020). A systematic review found that oral Chinese medicine was neither better nor inferior to acitretin, which may reduce the common adverse reactions of acitretin. (Zhang et al, 2015). 
The 11 studies included 54 herbs, of which the eight most used herbs include the following: Rhizoma Smilacis Glabrae (rhizome of Smilax glabra Roxb), Radix Paeoniae Rubra (root of Paeonia veitchii Lynch), Rhizoma Curcumae Aeruginosae (rhizome of Curcuma zedoaria [Christm.] Roscoe), Radix Salviae Miltiorrhizae (root and rhizome of Salvia miltiorrhiza Bunge), Radix Rehmanniae (root of Rehmannia glutinosa [Gaertn.] DC.), Caulis Spatholobi (dried lianoid stem of Spatholobus suberectus Dunn), Radix Arnebiae (root of Lithospermum erythrorhizon Sieb. et Zucc.) and Chinese angelica (root of Angelica sinensis [Oliv.] Diels.). Generally, the purpose of these traditional Chinese medicines included cooling, activating, and nourishing the blood. The ongoing high-quality randomized controlled double-blind clinical trials are shown in Table 3, which indicated that it is worthy of being investigated to promote clinical application. Pharmacological studies have demonstrated the mechanism of some drugs in the treatment of psoriasis. For instance, Rhizoma smilacis glabrae plays an anti-inflammatory and immunomodulatory role by inhibiting overactivated macrophages and regulating the activity of $\mathrm{T}$ lymphocytes (Jiang and $\mathrm{Xu}, 2003$ ). The main bioactive components of Rhizoma smilacis glabrae, including astilbin, neoastilbin, neoisoastilbin, isoastilbin, engeletin, and isoengeletin are all flavonoids (Zhang et al., 2019). Tanshinone IIA, the effective component of Radix salviae miltiorrhizae, can inhibit the proliferation of $\mathrm{KC}$, induce apoptosis, and block the cell cycle of KC (Li F. L. et al., 2012). Radix arnebiae can be used both internally and externally to treat psoriasis, which decreases IL17-induced VEGF expression by the inhibition of JAK2/STAT3 signaling and exerts an anti-inflammatory effect via proteasome inhibition ( $\mathrm{Lu}$ et al., 2011; Xu et al., 2014). Radix paeoniae rubra can inhibit the upregulation of pro-inflammatory mediators, such as tumor necrosis factor- $\alpha$ and IL-1 $\beta$ (Guo et al., 2012). Pharmacological studies have proved that Caulis spatholobi has the effect of increasing the expression of caspase- 3 and inhibiting human neutrophil elastase activity (Ha et al., 2004; Huang et al., 2013). These results demonstrate that the anti-inflammatory and immunomodulatory effects, and inhibition of epidermal cell proliferation by CHM contribute to its efficacy for psoriasis treatment.

This systematic review has some limitations. First, since we take high-quality RCT research studies as the starting point, satisfying trials with high quality are limited. Moreover, there are no high-quality double-blind placebo RCTs on CHM and Western medicine to better evaluate the efficacy and advantages of CHM. Second, only three trials (Yao et al., 2016; Li et al., 2017; Mao et al., 2019) had been registered in the Clinical Trials Registry Platform. Therefore, it is not possible to use the protocol to confirm no selective reporting. Third, although the methodological quality of the included trials was generally high based on the Jadad scale, there were still some methodological defects. Three (Wang, 2003; Mao et al., 2019; Li B. Y. et al., 2020) trials failed to report the specific randomized method, two trials failed to (Wang, 2003; Mao et al., 2019) report the concealment method, and only three trials (Yao et al., 2016; Li et al., 2017; Lv, 2018) reported the follow-up data. Therefore, the results of these studies should be interpreted carefully. Finally, it was difficult to unify the drug composition, doses and the course of treatment in the included trials. This may affect the validity of the research results. A large high-quality RCT with sufficient standardized information on the quality control, content, usage, and course of treatment of CHM should be conducted in future studies (Gagnier et al., 2006).

\section{CONCLUSION}

In summary, CHM appears safe and effective in treating patients with psoriasis and has a great impact in improving their quality of life, but does not lead to complete elimination of skin lesions and improvement in pruritus severity. No evidence is available on the ability of CHM to reduce the relapse the rate of psoriasis. All the included studies reported adverse events; overall, CHM was safe for the treatment of psoriasis.

\section{DATA AVAILABILITY STATEMENT}

The original contributions presented in the study are included in the article/Supplementary Material, further inquiries can be directed to the corresponding authors.

\section{AUTHOR CONTRIBUTIONS}

YL and JC conceived this study. YL and JC designed this study. $\mathrm{LK}, \mathrm{YZ}$, and $\mathrm{XD}$ searched the literature and extracted data. YL, $Y R$, and MX assessed the quality of trials and analyzed the data. $\mathrm{XS}$ and BL prepared the original manuscript draft. YR, MX and $\mathrm{XD}$ contributed to revise the manuscript. All authors have read and approved the final manuscript.

\section{FUNDING}

This study was supported by the National Key Research and Development Program of China (No. 2018YFC1705301), the National Natural Science Foundation of China (No. $81973860,81904214,81874470,82074427,82004235)$, the Shanghai Key Clinical Specialty Construction Project (No. shslczdzk05001), the Shanghai Three-year Action Plan for the Development of Traditional Chinese Medicine (No. ZY(20182020)-FWTX-4010, ZY(2018-2020)-FWTX-1008), the Shanghai Pujiang Talent Plan (No. 2020PJD067) and the Shanghai Science and Technology Commission (No. 20YF1450400, 18401932300).

\section{SUPPLEMENTARY MATERIAL}

The Supplementary Material for this article can be found online at: https://www.frontiersin.org/articles/10.3389/fphar.2020.599433/ full\#supplementary-material. 


\section{REFERENCES}

Armstrong, A. W., Harskamp, C. T., and Armstrong, E. J. (2013). Psoriasis and metabolic syndrome: a systematic review and meta-analysis of observational studies. J. Am. Acad. Dermatol. 68, 654-662. doi:10.1016/j.jaad.2012.08.015

Bahraini, P., Rajabi, M., Mansouri, P., Sarafian, G., Chalangari, R., and Azizian, Z. (2018). Turmeric tonic as a treatment in scalp psoriasis: a randomized placebocontrol clinical trial. J. Cosmet. Dermatol. 17, 461-466. doi:10.1111/jocd.12513

Chen, W. W. (2016). Study on the treatment of Psoriasis Vulgaris from Blood and Serum metabonomics. Master's thesis. Beijing (China): Beijing University of Chinese Medicine. [in Chinese].

Chen, Y., Guo, D. J., Deng, H., Wu, M. F., Zhang, Y. N., Li, S., et al. (2018). Acute and chronic toxicity of a polyherbal preparation - jueyin granules. BMC Compl. Alternative Med. 18, 148. doi:10.1186/s12906-018-2211-Z

Deng, S., May, B. H., Zhang, A. L., Lu, C., and Xue, C. C. L. (2013). Topical herbal medicine combined with pharmacotherapy for psoriasis: a systematic review and meta-analysis. Arch. Dermatol. Res. 305, 179-189. doi:10.1007/s00403-0131316-y

Dermatology Branch of Chinese Association of traditional Chinese medicine (2013). Evidence-based clinical practice guide of traditional Chinese medicine for psoriasis vulgaris. J. Tradit. Chin. Med. 55, 76-82. doi:10. 13288/j.11-2166/r.2014.01.021

Gagnier, J. J., Boon, H., Rochon, P., Moher, D., Barnes, J., and Bombardier, C. (2006). CONSORT Group.Reporting randomized, controlled trials of herbal interventions: an elaborated CONSORT statement. Ann. Intern. Med. 144, 364-367. doi:10.7326/0003-4819-144-5-200603070-00013

Griffiths, C. E., and Barker, J. (2007). Pathogenesis and clinical features of psoriasis. Lancet 370, 263-271. doi:10.1016/S0140-6736(07)61128-3

Guo, R. B., Wang, G. F., Zhao, A. P., Gu, J., Sun, X. L., and Hu, G. (2012). Paeoniflorin protects against ischemia-induced brain damages in rats via inhibiting MAPKs/NF-кБќлдгзатдг змаллатнрч рдсонмсдсћ PLoS One 7, e49701. doi:10.1371/journal.pone.0049701

Ha, E. S., Lee, E. O., Yoon, T. J., Kin, J. H., Park, J. O., Lim, N. C., et al. (2004). Methylene chloride fraction of Spatholobi Caulis induces apoptosis via caspase dependent pathway in U937 cell. Biol. Pharm. Bull. 27, 1348-1352. doi:10.1248/ bpb. 27.1348

Hawkes, J. E., Chan, T. C., and Krueger, J. G. (2017). Psoriasis pathogenesis and the development of novel targeted immune therapies. J. Allergy Clin. Immunol. 140, 645-653. doi:10.1016/j.jaci.2017.07.004

Huang, Y., Chen, L., Feng, L., Guo, F., and Li, Y. (2013). Characterization of total phenolic constituents from the stems of Spatholobus suberectus using LCDAD-MS(n) and their inhibitory effect on human neutrophil elastase activity. Molecules 18, 7549-7556. doi:10.3390/molecules18077549

Jiang, J., and $\mathrm{Xu}, \mathrm{Q}$. (2003). Immunomodulatory activity of the aqueous extract from rhizome of Smilax glabra in the later phase of adjuvant-induced arthritis in rats. J. Ethnopharmacol. 85, 53-59. doi:10.1016/s0378-8741(02)00340-9

Kuai, L., Song, J., Zhang, R., Xing, M., Luo, Y., Ru, Y., et al. (2020). Uncovering the mechanism of jueyin granules in the treatment of psoriasis using network pharmacology. J. Ethnopharmacol. 262, 113214. doi:10.1016/j.jep.2020. 113214

Kurd, S. K., Troxel, A. B., Crits-Christoph, P., and Gelfand, J. M. (2010). The risk of depression, anxiety, and suicidality in patients with psoriasis: a populationbased cohort study. Arch. Dermatol. 146, 891-895. doi:10.1001/archdermatol. 2010.186

Li, F. L., Xu, R., Zeng, Q. C., Li, X., Chen, J., Wang, Y. F., et al. (2012). Tanshinone IIA inhibits growth of keratinocytes through cell cycle arrest and apoptosis: underlying treatment mechanism of psoriasis. Evid. Based Compl. Alternat. Med. 2012, 927658. doi:10.1155/2012/927658

Li, N., Li, Y. Q., Li, H. Y., Guo, W., and Bai, Y. P. (2012). Efficacy of externally applied Chinese herbal drugs in treating psoriasis: a systematic review. Chin. J. Integr. Med. 18, 222-229. doi:10.1007/s11655-012-1004-3

Li, N., Zhao, W. B., Xing, J. M., Liu, J. P., Zhang, G. Z., Zhang, Y. B., et al. (2017). Chinese herbal Pulian ointment in treating psoriasis vulgaris of blood-heat syndrome: a multi-center, double-blind, randomized, placebo-controlled trial. BMC Compl. Alternat. Med. 17, 264. doi:10.1186/s12906-017-1631-5

Li, B. Y., Sun, H. Y., Wu, M., Yan, X. X., Yu, M. L., Zhang, C. X., et al. (2020). A Single-Center randomized double-blind placebo-controlled clinical trial of
Kunxian capsule in the treatment of psoriasis vulgaris. Chin J Lep Skin Dis. 36, 161-164. doi:10.12144/zgmfskin202003161

Li, S., Zhang, C., Zhang, H. Y., Zhang, H. Y., Zhou, M., Wang, S. N., et al. (2020). Efficacy and safety of jueyin granules for patients with mild-to-moderate psoriasis vulgaris: protocol for a multicenter randomized placebo-controlled trial. Evid. Based Compl. Alternat. Med. 2020, 8942301. doi:10.1155/2020/ 8942301

Liberati, A., Altman, D. G., Tetzlaff, J., Mulrow, C., Gøtzsche, P. C., Ioannidis, J. P., et al. (2009). The PRISMA statement for reporting systematic reviews and meta-analyses of studies that evaluate healthcare interventions: explanation and elaboration. BMJ 21, b2700. doi:10.1136/bmj.b2700

Lowes, M. A., Bowcock, A. M., and Krueger, J. G. (2007). Review article pathogenesis and therapy of psoriasis. Nature 445, 866-873. doi:10.1038/nature05663

Lu, L., Qin, A. P., Huang, H. B., Zhou, P., Zhang, C. Y., Liu, N. N., et al. (2011). Shikonin extracted from medicinal Chinese herbs exerts anti-inflammatory effect via proteasome inhibition. Eur. J. Pharmacol. 658, 242-247. doi:10.1016/j. ejphar.2011.02.043

Lv, M., (2018). Clinical observation and mechanism exploration of PSORI-CM02, Yinxieling tablet on stable plaque psoriasis. Master's thesis. Guangzhou (China): Guangzhou University of Chinese Medicine [in Chinese].

Mao, C. L., Wu, Y. Y., Zhou, D. M., Xu, W. J., and Wang, J. S. (2019). The efficiency and safety of the Chinese herbal medicine liang xue huo xue decoction (LXHXD) in patients with psoriasis vulgaris of blood heat syndrome. Int. J. Clin. Exp. Med. 12, 6020-6025.

Michalek, I. M., Loring, B., and John, S. M. (2017). A systematic review of worldwide epidemiology of psoriasis. J Eur Acad Dermatol. 31, 205-212. doi:10.1111/jdv.13854

Oliveira, M. F. S. P., Rocha, B. O., and Duarte, G. V. (2015). Psoriasis: classical and emerging comorbidities. Anais Brasileiros De Dermatologia. 90, 9-20. doi:10. 1590/abd1806-4841.20153038

Psoriasis Professional Committee of Dermatology and venereology Branch of Chinese Medical Association (2019). Guidelines for the diagnosis and treatment of Psoriasis in China (2018 simplified version). Chin. J. Dermatol. 52, 223-230. doi:10.3760/cma.j.issn.0412-4030.2019.04.001

Ramanunny, A. K., Wadhwa, S., Singh, S. K., Sharma, D. S., Khursheed, R., and Awasthi, A. (2020). Treatment strategies against psoriasis: principle, perspectives and practices. Curr. Drug Deliv. 17, 52-73. doi:10.2174/1567201816666191120120551

Ru, Y., Li, H., Zhang, R., Luo, Y., Song, J., Kuai, L., et al. (2020). Role of keratinocytes and immune cells in the anti-inflammatory effects of Tripterygium wilfordii Hook. f. in a murine model of psoriasis. Phytomedicine 77, 153299. doi:10.1016/j.phymed.2020.153299

Ru, Y., Yan, X. N., Yang, Q. S., Gong, L. P., Li, L. E., Chen, J., et al. (2019). Oral Taodan granules for mild-to-moderate psoriasis vulgaris: protocol for a randomized, double-blind, multicenter clinical trial. Ann. Transl. Med. 7, 488. doi:10.21037/atm.2019.09.05

She, Y. Y. (2017). A Clinical research on the treatment of psoriasis vulgaris in stationary stag blood dryness syndrome, blood stasis syndrome with Calm-theMind-and-Relieve-Intching formula. Master's thesis. Beijing (China): China Academy of Chinese Medicine Sciences [in Chinese].

Tangtatco, J. A. A., and Lara-Corrales, I. (2017). Update in the management of pediatric psoriasis. Curr. Opin. Pediatr. 29, 434. doi:10.1097/MOP. 0000000000000517

Wang, G., Bai, F., Tian, Z., Fan, L., and Lei, M. (2020). Balneotherapy with Chinese herbal medicine prolongs the remission period in patients with psoriasis vulgaris. Dermatol. Ther. 33, e13351. doi:10.1111/dth.13351

Wang, Z. C. (2003). Compound Indigo Naturalis Capsules for the treatment of psoriasis: a randomised controlled trial. J Chin Tolk Ther. 11, 48-49. doi:10. 3969/j.issn.1007-5798.2003.01.077

Xiao, M., Qian, C. Y., Luo, X., Yang, M. B., Zhang, Y. F., Wu, C. Y., et al. (2019). Impact of the Chinese herbal medicines on dual antiplatelet therapy with clopidogrel and aspirin: pharmacokinetics and pharmacodynamics outcomes and related mechanisms in rats. J. Ethnopharmacol. 235, 100-110. doi:10.1016/ j.jep.2019.01.040

Xu, Y., Xu, X., Gao, X., Chen, H., and Geng, L. (2014). Shikonin suppresses IL-17induced VEGF expression via blockage of JAK2/STAT3 pathway. Int. Immunopharm. 19, 327-333. doi:10.1016/j.intimp.2014.01.027 
Yan, J. T., Wang, Q. G., Liu, X. Q., Li, B., Ru, Y., Hong, S., et al. (2020). The immune status of patients with psoriasis vulgaris of blood-stasis syndrome and blooddryness syndrome: a qualitative evidence synthesis. Ann. Palliat. Med. 9,1382-1395. doi:10.21037/apm-19-432

Yang, L., Zhang, C. S., May, B., Yu, J., Guo, X., Zhang, A. L., et al. (2015). Efficacy of combining oral Chinese herbal medicine and NB-UVB in treating psoriasis vulgaris: a systematic review and meta-analysis. Chin. Med. 10, 27. doi:10.1186/ s13020-015-0060-y

Yao, D. N., Lu, C. J., Wen, Z. H., Yan, Y. H., Xuan, M. L., Li, X. Y., et al. (2016). Oral PSORI-CM01, a Chinese herbal formula, plus topical sequential therapy for moderate-to-severe psoriasis vulgaris: pilot study for a double-blind, randomized, placebo-controlled trial. Trials 17, 140. doi:10.1186/s13063-016-1272-x

Zandi, S., Meymandi, S. S., Gorji, S. H., and Shahrebabak, F. S. (2011). Evaluation of quality of life in patients with psoriasis. Dermatol. Cosmet. 2, 166-173.

Zhang, C. S., Yu, J. J., Parker, S., Parker, S., Zhang, A. L., May, B., et al. (2015). Oral Chinese herbal medicine combined with pharmacotherapy for psoriasis vulgaris: a systematic review. Int. J. Dermatol. 53, 1305-1318. doi:10.1111/ijd.12607

Zhang, L., Zheng, D., and Zhang, Q. F., (2019). Purification of total flavonoids from Rhizoma Smilacis Glabrae through cyclodextrin-assisted extraction and resin adsorption. Food Sci. Nutr. 7, 449-456. doi:10.1002/fsn3.809

Zhang, Z. Z. (2018). Effect of treatment and mechanism with Chinese medicine PSORI-CM01, balneotherapy and coal tar on psoriasis vulgaris. Master's thesis. Guangzhou (China): Guangzhou University of Chinese Medicine [in Chinese].
Zheng, Q., Jiang, W. C., Sun, X. Y., Ma, T., Xu, W. B., and Shen, F. (2019). Total glucosides of paeony for the treatment of psoriasis: a systematic review and meta-analysis of randomized controlled trials. Phytomedicine. 62: 152940. doi:10.1016/j.phymed.2019.152940

Zhou, D. M. (2011). Wang Jusheng's academic thoughts and clinical experiences and the clinical study of treating psoriasis through blood differentiation. Master's thesis. Beijing (China): Beijing University of Chinese Medicine [in Chinese].

Zhou, M. J. (2012). Study of the Mechanisms of Liangxuehuoxue Complex Prescription on Progressive Psoriasis. Master's thesis. Dalian (China): Dalian Medical University.

Conflict of Interest: The authors declare that the research was conducted in the absence of any commercial or financial relationships that could be construed as a potential conflict of interest.

Copyright (c) 2021 Luo, Chen, Kuai, Zhang, Ding, Luo, Ru, Xing, Li, Sun, Li and Li. This is an open-access article distributed under the terms of the Creative Commons Attribution License (CC BY). The use, distribution or reproduction in other forums is permitted, provided the original author(s) and the copyright owner(s) are credited and that the original publication in this journal is cited, in accordance with accepted academic practice. No use, distribution or reproduction is permitted which does not comply with these terms. 